\title{
A MARÉ DIZ NÃO AO CORONAVÍRUS: A EXPERIÊNCIA DE ATIVISMO DA ORGANIZAÇÃO REDES DA MARÉ NO ENFRENTAMENTO DA PANDEMIA
}

MARÉ SAYS NO TO CORONAVIRUS: REDES DA MARÉ'S EXPERIENCE IN CONFRONTING PANDEMIC

Julia Ventura

Doutora em Ciências Sociais pela Pontifícia Universidade Católica do Rio de Janeiro (PUC-Rio), atuando com projetos sociais desde 2005 em organizações da sociedade civil, como a FASE, o Viva Rio, a Redes da Maré e o UNIperiferias. Atualmente é gestora do Programa Aluno Presente na Associação Cidade Escola Aprendiz, coordenando projetos de enfrentamento da exclusão escolar em vários municípios do país. Também atuou como professora de Sociologia no Ensino Médio e pesquisadora, sendo autora de artigos acadêmicos e profissionais. 


\section{RESUMO}

Com o advento da pandemia do coronavírus, as populações de periferias e favelas brasileiras tornaram-se o foco de maior risco devido ao quadro histórico de desigualdades sociais nesses territórios. O ativismo das forças sociais que compõem a sociedade civil, nesse contexto, tem assumido a centralidade do trabalho de proteção da população mais socialmente vulnerável, no vácuo deixado pelas políticas públicas. Neste estudo, é analisada a experiência de uma campanha conduzida pela organização não governamental Redes da Maré, cuja origem vem de uma trajetória de lutas sociais dos moradores das favelas que compõem o bairro da Maré, na periferia do Rio de Janeiro, como um exemplo decisivo para a sobrevivência dos moradores locais e promoção de direitos, valendo-se da mobilização de um amplo conjunto de atores e consolidando uma rede solidária e potente, que foi capaz de beneficiar, ao longo de 2020, mais de 50 mil pessoas diretamente.

Palavras-chave: periferias; ativismo; sociedade civil; pandemia do coronavírus.

\section{ABSTRACT}

With the advent of the coronavirus pandemic in Brazil, the populations of Brazilian peripheries and slums have become the focus of greatest social risk, due to the historical issue of social inequalities that conformed these territories. The activism of the social forces that compund civil society, in this context, has assumed the centrality of the social protection work of the most socially vulnerable population, in the vacuum left by public policies. In this study, the experience of a campaign conducted by Redes da Maré, a non-governmental organization originated by the trajectory of social struggles of the residents of the favelas under the neighborhood of Maré, is being analyzed as a decisive example for the survival of local residents and promotion of rights, due to the mobilization of a wide range of actors and consolidating a solidary and potent network capable of benefiting more than 50 thousand people directly in 2020.

Keywords: peripheries; activism; civil society; coronavirus pandemic. 


\section{Introdução}

O papel da sociedade civil brasileira na conquista dos direitos fundamentais se intensificou ao longo do século $\mathrm{XX}$, entre avanços e retrocessos no processo de democratização e na consolidação da cidadania, até um marco de conquistas que foi a Constituição de 1988. A conquista dos direitos "pela letra fria da lei", contudo, foi combinada ao descompasso da efetivação desses mesmos direitos, dependendo da mobilização social ao longo de décadas para que alguns avanços fossem alcançados. Apesar do histórico autoritário do Estado, condutor de uma modernização regulada pelo crescimento econômico, desacompanhado das reformas sociais distributivas e fiel à manutenção dos privilégios das elites, os movimentos populares e a organização coletiva têm se comportado como pilares da resiliência periférica.

Deve-se, em parte, ao trabalho de base conduzido pelo setor progressista da igreja católica no Brasil, em meados do século XX, por meio das pastorais da juventude, da terra e do trabalho, a ampliação dos movimentos sociais organizados e o aquecimento do associativismo civil. Seguidos pelos movimentos sindicais e seus desdobramentos na política institucional, somaram-se a esse conjunto de forças sociais. Com mais intensidade a partir da década de 1990, vieram as Organizações não Governamentais (ONGs), de interesse público e social, num contexto de redemocratização, globalização e ponderação sobre a participação civil como público não estatal na reforma do Estado.

As ONGs passaram a integrar um tecido social com potencial de ativação política das ações de solidariedade social existentes nos territórios segregados das cidades. As lutas redistributivas, baseadas nas reivindicações pelos direitos sociais, como educação pública e seguridade social, logo foram acompanhadas das lutas identitárias, com destaque para o enfrentamento ao racismo e ao machismo estruturais, produzindo, com seu prolongamento pelo século XXI, estímulo às vozes emergentes dos territórios periféricos por meio do seu "lugar de fala".

As periferias urbanas, na qualidade de espaços de sociabilidade marginal numa sociedade de classes, apresentam em sua origem um histórico de vida comunitária solidária incentivada pelas necessidades decorrentes das condições sociais de seus habitantes, pelas relações familiares locais e pelas redes de assistencialismo lideradas por instituições sociais e religiosas. Assim, são relatados como exemplos da solidariedade comunitária os inúmeros mutirões de moradores de favelas na cidade do Rio de Janeiro, responsáveis pela construção de casas e estabelecimentos para uso próprio, numa espécie de reciprocidade diante da escassez. O próprio surgimento da primeira favela carioca, no atual Morro da Providência, deve-se à organização coletiva e ao protagonismo político dos 
primeiros ocupantes dessas encostas, que exigiam do Estado o pagamento prometido por sua participação na Guerra de Canudos (VALLADARES, 2005).

Por se configurarem locais que se desenvolveram originalmente sem a presença de instituições públicas do Estado e, ao mesmo tempo, sem a formalização fundiária das propriedades privadas, a favela - enquanto espaço simbólico de uso coletivo - constituiuse por meio da iniciativa comunitária de seus habitantes, que contavam apenas uns com os outros para construir e organizar suas habitações e sua convivência. Por outro lado, aos olhos do "asfalto", a favela passou a simbolizar um território "perigoso", passível de controle pelas forças policiais, por causa da criminalização em razão da cor, da condição de "vagabundagem" e demais estigmas direcionados aos trabalhadores informais e às pessoas negras descendentes de escravizados, numa perspectiva higienista que predominou no país na passagem do século XIX para o XX.

A instituição dos territórios periféricos como sede para grupos de narcotraficantes, já nas últimas décadas do século XX, acompanhou o histórico de desregulação estatal e agravou ainda mais a repressão policial sobre seu cotidiano. Essa repressão foi legitimada pelas fronteiras simbólicas que delimitaram o contorno do espaço segregado em que os direitos humanos estabelecidos na Carta de 88 não se concretizam e nem sequer são compreendidos como referência de desenvolvimento social, além de estabelecer uma sociabilidade violenta (SILVA, 2004) agregada às insuficiências do estado de direito.

Diante disso, coube aos próprios moradores de favelas e periferias a tarefa de ressignificação de sua existência nesses espaços, assim como a produção de respostas endógenas à sua sobrevivência, entre elas a autorregulação da vida econômica e a politização de suas demandas sociais para a implementação de políticas públicas em seu benefício. Nesse sentido, cabe destacar o surgimento de uma intelectualidade orgânica de origem periférica a partir das primeiras lideranças políticas e gerações universitárias que, ao romperem as fronteiras da desigualdade de acesso à política institucional e ao Ensino Superior, assumiram uma narrativa contundente de afirmação da periferia como fonte legítima de protagonismo político e de autointerpretação sociológica.

De acordo com Fernandes et al. (2018), a desmoralização dos moradores de favela, tratados como "cidadãos de segunda classe" ou "não cidadãos", foi historicamente utilizada para reter nesse território os moradores em condições de desigualdade. Contudo favelas e periferias, ao contrário, precisam ser compreendidas como "espaços de múltiplas existências", imbuídas de forças que traduzem as "novas configurações do ativismo social" por meio da potência transformadora das práticas daqueles simbolicamente destituídos de representatividade social, cultural e política. 
Segundo os autores, "a falta do reconhecimento das forças positivas das favelas e periferias tem historicamente mitigado a possibilidade de considerar um projeto de urbanização que trate a favela e a periferia como possível ponto de partida" (p. 8), em vez de um depositório passivo de intervenções arbitrárias e "supostamente democráticas", que ignoram a potência desse território. Portanto é imprescindível reconhecer o poder inventivo dos moradores de favelas e periferias, como grupos marcados pela desigualdade social e estigmatizados pela violência, como referência para a construção do que os autores denominam de "Paradigma da Potência". Sob essa perspectiva, "o estilo de vida (em vez das condições de vida) é reconhecido pelos termos que lhes são próprios (e não comparado aos padrões hegemônicos presentes na cidade)" (p. 9).

Territórios populares e seus sujeitos, portanto, constituem-se como a vanguarda da sociedade civil contemporânea, pois detêm a real inventividade de uma vida urbana plena, e são capazes de criar, por meio de suas práticas da experiência periférica, uma resposta autêntica à cidadania de fato. Em vez de terem suas existências desvalorizadas e depreciadas como expressões da ausência e da privação, entre outras representações negativas, é preciso reconhecer práticas, estéticas e estratégias provenientes dos sujeitos periféricos como sendo indiscutivelmente políticas e inovadoras, além de serem as mais capazes de protagonizar as conquistas ainda necessárias à efetivação da democracia social.

Diante desse recorte analítico, torna-se de suma importância compreender como o ativismo periférico tem orquestrado suas forças num momento dramático pelo qual passa a sociedade brasileira. As soluções encontradas ou experimentadas nesses contextos têm o potencial de assumir o centro da inventividade social, da qual se pode esperar uma renovação cívica orientada à retomada da perspectiva de direitos, atualmente foco de um embate político civilizatório.

A atuação das organizações sociais e lideranças comunitárias nos territórios populares para a assistência à população local, no contexto da atual crise pandêmica que vem assolando nosso país com o advento do novo coronavírus, consiste numa experiência de sociabilidade periférica que reaviva o ativismo local sem o qual as periferias se encontrariam relegadas ao ocaso. Diante da inevitabilidade da tragédia, pulularam iniciativas advindas de organizações da sociedade civil como uma resposta emergencial a toda sorte de demandas, desde a subsistência básica, como evitar a fome, até o acesso a informações e recursos para a prevenção de contágio da doença. Num cenário de crise social aguda que se anunciava, mais uma vez coube à sociedade civil agir por meio da solidariedade comunitária e da luta pela garantia de direitos, como historicamente ocorre nas periferias brasileiras. 
Neste artigo, será abordada a experiência particular de uma ONG que há décadas atua no complexo de favelas da Maré, constituída por moradores locais com histórico de participação associativa e liderança política para a promoção de direitos sociais, culturais, políticos e civis. A ONG Redes de Desenvolvimento da Maré ${ }^{1}$ realizou uma campanha emergencial - Maré Diz Não ao Coronavírus - para apoio às famílias em situação de vulnerabilidade, residentes em qualquer uma das 16 favelas que compõem o bairro da Maré, situado na Zona Norte da cidade do Rio de Janeiro. Atuando como um projeto mobilizador, tal qual preconizaram Toro e Werneck (1996), a Redes da Maré, como é conhecida, atuou mediante uma metodologia que apostou no "envolvimento ativo do cidadão, da organização social, da empresa, nos rumos e acontecimentos em nossa sociedade".

A campanha, iniciada em março de 2020, na iminência das notícias sobre a chegada do coronavírus ao Brasil, beneficiou mais de 54 mil pessoas até outubro do mesmo ano, aproximadamente um terço da população total. De acordo com a idealizadora e diretora da instituição, Eliana Sousa Silva, ao tomar conhecimento do início da pandemia no país, foi imediata a constatação de que o risco sobre a população de baixa renda e residente em periferias seria devastador, tendo em vista as precárias condições socioeconômicas de uma parte considerável da população, como as condições de moradia, alimentação, saneamento, renda e acesso à informação, dentre outras. Uma atuação de larga escala direcionada a esse público, portanto, se fez imediatamente necessária para ajudar a mitigar os impactos sobre as famílias da Maré e, no limite, salvar vidas.

Diante da escalada relevante que a campanha - e seus desdobramentos - alcançou, conhecer e compreender seus princípios, seu funcionamento e seus resultados constitui uma importante contribuição para a sociologia dos movimentos sociais, comprometida com o estudo sobre a atuação da sociedade civil na construção da democracia social, capaz de efetivar os direitos da população e assegurar de maneira plena sua cidadania, em especial num contexto de crise humanitária. O papel decisivo do ativismo periférico nesse contexto reforça ainda mais a ideia de que as verdadeiras transformações sociais virão, inevitavelmente, da potência da periferia.

\section{Quando o ativismo periférico se tornou mais necessário}

No Brasil, a pandemia causada pelo novo coronavírus teve início oficialmente em março de 2020, com a chegada do vírus por meio de viajantes internacionais que,

\footnotetext{
${ }^{1}$ Criada em 2007, fruto de uma dissidência do antigo Centro de Estudos e Ações Solidárias da Maré (CEASM), fundado em 1997 com o projeto do pré-vestibular comunitário que viabilizou que as primeiras gerações de jovens mareenses chegassem à universidade.
} 
contaminados, disseminaram a tragédia social anunciada. A primeira vítima da doença no estado do Rio de Janeiro, entretanto, foi uma empregada doméstica, de 63 anos, que trabalhava na casa de uma pessoa recém-chegada da Itália, a qual mesmo apresentando os sintomas da doença, não dispensou a funcionária.

O fato retrata bem o cenário do que transcorreu a seguir em todo o país: os efeitos da desigualdade social brasileira tiveram impacto nocivo sobre a distribuição da doença entre a população, tornando-se mais intensos nas camadas sociais mais pobres. $\mathrm{O}$ isolamento social necessário à contenção do vírus foi amplamente negligenciado por fatores diversos, desde posicionamentos políticos negacionistas até a imperiosa necessidade de manter-se trabalhando presencialmente para boa parte da população cuja renda familiar não poderia ser obtida de outra maneira.

Os governos municipal e estadual, contudo, demonstraram-se limitados à oferta da proteção social e sanitária, em especial aos grupos mais socialmente vulneráveis, apesar de toda a mobilização dos profissionais do Sistema Único de Saúde (SUS). Em um município como o do Rio de Janeiro - no qual cerca de um terço da população de quase sete milhões de habitantes reside em favela, em moradias de poucos cômodos ou de apenas um, sem ventilação e saneamento adequados, e com média de quatro a seis moradores -, a perspectiva de controle da pandemia via isolamento social, apesar de extremamente necessário, apresentou desafios complexos aos quais apenas uma política pública ágil, abrangente e eficaz poderia responder. No entanto ela não ocorreu.

De acordo com um levantamento iniciado pela Articulação por Direitos na Pandemia, ${ }^{3}$ composta por dezenas de entidades, dentre elas o Observatório das Metrópoles e o Dicionário de Favelas Marielle Franco, as dificuldades dos moradores de favelas em manter o isolamento se fundamentaram na necessidade de trabalhar ou na inadequação da moradia que, por vezes, não comporta abrigar todos da família, além da ausência de campanhas informativas por parte do poder público para incentivar a adesão da população ao isolamento social. O estudo aponta ainda que, junto com os limites da infraestrutura urbana em favelas e periferias, com destaque para a falta de acesso à água, a população teve outras dificuldades, como as de alcance aos programas emergenciais de auxílio financeiro - tendo em vista a necessidade de informatização e a inclusão digital para cadastramento e recebimento do benefício -, perda de renda e insegurança alimentar.

\footnotetext{
${ }^{2}$ Disponível em: <https://g1.globo.com/rj/rio-de-janeiro/noticia/2020/03/19/rj-confirma-a-primeira-morte-porcoronavirus.ghtml>. Acesso em: 01 abr. 2021.

${ }^{3}$ Disponível em: <https://uploads.strikinglycdn.com/files/6c7dabc7-bd51-4be3-901d5b1bee09457a/Sistematiza\%C3\%A7\%C3\%A3o_Nacional_Covid_-_vers\%C3\%A3o_final.pdf?id=252309>. Acesso em: 18 mar. 2021.
} 
Dados nacionais reafirmam essas constatações quando indicaram o crescimento da taxa de desemprego a índices jamais registrados desde que a série histórica foi iniciada, em 2012, pelo IBGE. Segundo dados da Pesquisa Nacional por Amostra de Domicílios Contínua (PNAD), a crise no mercado de trabalho, agravada pela pandemia, fez o país terminar 2020 com uma taxa média de desemprego de I3,5\%, contabilizando I3,4 milhões de desempregados, além de 31,2 milhões de brasileiros subocupados para os quais falta trabalho. O número de desalentados, que desistiram de procurar trabalho, atingiu 5,5 milhões de pessoas em 2020, uma alta de I6,I\% em relação ao ano anterior. ${ }^{4}$ Segundo o relatório, o impacto da crise pode ser medido pelo fechamento de vagas. Em apenas um ano, 7,3 milhões de postos de trabalho sumiram. No mercado formal, foram eliminados 2,6 milhões de postos de trabalho em 2020. Junto com o risco de adoecimento e morte pela Covid-I9, o desemprego e a fome voltaram a assolar o país.

Além do auxílio emergencial não ter sido suficiente, ter sido interrompido e reduzido de valor, bem como não ter alcançado toda a população - em especial os que mais precisavam dele -, as demais políticas federais, cuja capacidade de redução dos impactos da pandemia teria sido essencial para antecipar a saída da crise, e outras insuficiências podem ser destacadas. Segundo um relatório publicado pelo Tribunal de Contas da União (TCU), ${ }^{5}$ o Ministério da Saúde gastou somente $29 \%$ do dinheiro que recebeu para as ações de combate ao coronavírus em 2020. ${ }^{6}$ Dos $\mathrm{R} \$ 38$ bilhões disponíveis, o ministério só pagou efetivamente R \$ II,4 bilhões para combater o coronavírus. O relatório ainda chamou atenção para o fato de que os estados do Pará e do Rio de Janeiro, apesar de terem, à época, respectivamente, a segunda e a terceira maior taxa de mortalidade por Covid-I9, representaram duas das três unidades da federação que menos receberam recursos para enfrentamento da pandemia.

Muitos outros exemplos de incompetência - ou mesmo de negligência criminosa dos governos de quaisquer dos entes federativos - poderiam ser destacados aqui, porém não é esse o objetivo deste artigo; senão sinalizar que, diante de um cenário de incertezas em relação à capacidade de as políticas públicas atuarem de maneira eficaz na proteção da população, as organizações da sociedade civil tiveram um papel determinante que merece ser compartilhado.

\footnotetext{
${ }^{4}$ Disponível em: <https://economia.uol.com.br/empregos-e-carreiras/noticias/redacao/2021/02/26/desemprego---pnadcontinua---dezembro-

2020.htm\#: :text=Compara\%C3\%A7\%C3\%A3o\%20anual\&text=Desalentados\%20(desistiram\%20de\%20procurar\%20trabalho,7 \%25\%20em\%20rela\%C3\%A7\%C3\%A30\%20a\%202019>. Acesso em: 18 mar. 2021.

${ }^{5}$ Disponível em: <https://www1.folha.uol.com.br/cotidiano/2020/07/ministerio-da-saude-gastou-menos-de-13-da-verba-paracovid-diz-tcu.shtml>. Acesso em: 20 mar. 2021.

${ }^{6}$ A análise abrange os gastos da pasta desde março, quando o governo decretou estado de calamidade pública no país, até julho de 2020.
} 
A Maré é uma região localizada às margens da Baía de Guanabara e atualmente é delimitada pela RJ-O7I, oficialmente denominada Rodovia Expressa Presidente João Goulart e popularmente conhecida como Linha Vermelha, cortada pela Linha Amarela e o trecho da BR-IOI denominado Avenida Brasil, três das principais vias de acesso à cidade, na Zona Norte do Rio de Janeiro. Assim, hoje, qualquer pessoa que entra no Rio e tenha que se direcionar para a Zona Sul ou para a Zona Norte ou, ainda, chegar ao aeroporto internacional precisa passar pela Maré. Essa localização a coloca em posição privilegiada, pois qualquer acontecimento na Maré repercute na cidade. (NÓBREGA JÚNIOR, 2OI2)

A história de um dos maiores complexos de favelas do país é contemporânea ao processo de industrialização da cidade, composto por um fluxo migratório intenso que trouxe trabalhadores oriundos principalmente da região Nordeste do país para compor a mão de obra necessária às obras de infraestrutura de expansão urbana, sobretudo após a década de 1940. Com a implementação do projeto industrial, os empreendimentos começaram a se descentralizar, de modo que as empresas de médio porte se estabeleceram no bairro de São Cristóvão, e as de grande porte expandiram em direção aos subúrbios pelas ferrovias. Assim, parcelas da população foram atraídas para esses locais. O marco da ocupação inicial da Maré se deu por ocasião da construção da variante Rio-Petrópolis, atual Avenida Brasil, construída paralelamente à Baía da Guanabara com o objetivo de ligar o centro da cidade aos distantes subúrbios e alargar a malha industrial da cidade.

As obras da Avenida Brasil estimularam a ocupação da Maré, construindo aterramentos e vias de acessos, e atraindo trabalhadores para se estabelecerem em seu entorno. Outro empreendimento importante na região foi a construção da Refinaria de Manguinhos (em I954), que consolidou a área como polo de desenvolvimento industrial com ampla oferta de empregos e oportunidades econômicas. Deve-se também à edificação da Cidade Universitária - atual Universidade Federal do Rio de Janeiro (UFRJ) -, a ocupação do Morro do Timbau, uma das nove comunidades originais da Maré com os registros mais antigos de ocupação, datados de 1939.

A ocupação da Maré, iniciada na década de 1940, teve um fluxo gradual de crescimento, passando a abrigar temporariamente famílias removidas de outras favelas cariocas. A política habitacional que se desenvolveu nesse período foi organizada a partir do Código de Obras (1937) que, por sua vez, deu origem aos Parques Proletários Provisórios (PPPs), os quais passaram a ser construídos na cidade a fim de promover a remoção e a realocação de famílias entre as favelas então existentes na Zona Sul, como na Gávea e no 
Morro do Pinto, para regiões ao norte e nos subúrbios. Nesse processo, os parques criados na Maré para moradia provisória tornaram-se permanentes e passaram a receber mais habitantes do que o planejado, deixando a infraestrutura local insuficiente e dando origem a novas favelas no entorno.

Por outro lado, a organização coletiva dos moradores foi decisiva para evitar remoções por parte do Estado e demandar melhores condições de saneamento, acesso à água e à pavimentação, dentre outras. Nesse período, surgiram as primeiras associações de moradores de favelas, com o protagonismo de mobilização dos moradores. Em resposta ao "problema moral" que a favela passara a representar no cenário da cidade (BURGOS, 2006), foi criada a Fundação Leão XIII, uma parceria entre a prefeitura e a arquidiocese católica, com o objetivo de promover a assistência social dos moradores, de um lado, e frear o risco do "comunismo" nas favelas, de outro. A fundação atuou entre 1947 e 1954 em 34 favelas da cidade, dentre as quais a Maré, realizando alguns serviços básicos, como saneamento, eletricidade e rede viária (NÓBREGA JÚNIOR, 2OI2).

Para Silva e Barbosa (2005), contudo, as ações da Fundação Leão XIII, apesar de controladoras e cerceadoras, pois substituíam parcialmente o papel do Estado, possibilitaram certo grau de organização associativa. De acordo com Burgos (2006), esse modelo de intervenção social não foi capaz de inibir completamente a articulação entre os moradores das favelas e os segmentos políticos, de modo que a partir da década de 1950 deu-se a intensificação da ligação entre líderes comunitários e partidos políticos, além de uma ampliação da intelligentsia orgânica e da aproximação de acadêmicos, que passaram não só a frequentar esses espaços como também refletir sobre eles.

Os autores apontam, entretanto, que a política de remoções não apenas permaneceu como se intensificou ao longo das décadas seguintes, despejando mais de 100 mil moradores, entre 1968 e 1975, oriundos de aproximadamente 60 favelas da cidade. $\mathrm{O}$ "remocionismo", como denomina o autor, contribuiu para a destruição dos vínculos horizontais que vinham sendo elaborados e subverteu a natureza representativa das associações de moradores, tornando-as porta-vozes do Estado junto às favelas, o que comprometeu a democratização das relações dentro da favela.

A atuação da igreja católica no interior das favelas seguiu um caminho contraditório num equilíbrio entre controle moral e incentivo associativo, sendo a Maré um caso nítido dessa relação. Osurgimento das lideranças que ali fundaram as organizações sociais, dentre as quais a Redes da Maré, tiveram na passagem pelos grupos jovens católicos uma influência importante de ação coletiva em suas trajetórias, sendo levadas às suas experiências nas associações de moradores e, posteriormente, à criação de organizações sociais e participação na política eleitoral. A criação da Redes da Maré deve ser considerada, assim como os projetos 
que realiza, portanto, como a materialização de um longo processo de ações, pesquisas e reflexões desenvolvidas nas e com as comunidades da Maré. A trajetória social e profissional de seu coletivo fundador é caracterizada pela atuação nos campos da educação, da cultura e da arte; na segurança pública, na comunicação e no desenvolvimento territorial a partir de sua vivência em diferentes espaços populares. ${ }^{7}$

Com a redemocratização, a Maré passou por muitas transformações e ganhou status oficial de bairro em 1994. Atualmente, sua população é estimada em aproximadamente I40 mil habitantes, sendo um bairro com mais habitantes do que os demais $96 \%$ municípios brasileiros. Caso fosse um município, seria o $2 \mathrm{I}^{\circ}$ mais populoso do estado do Rio de Janeiro ou o I $2^{\circ}$ da região metropolitana. Além disso, a Maré representa mais de $9 \%$ da população residente em favelas no município do Rio de Janeiro, e quase 21\% de todos os residentes em favelas da Área de Planejamento em que está localizada, a $\mathrm{AP}_{3}$ (Zona Norte), região da cidade com o maior número de moradores em favelas (SOUSA SILVA; MARINHO, 20I8). ${ }^{8}$ Apesar de sua amplitude e dos avanços acumulados nas últimas décadas por meio de programas governamentais de moradia popular, o bairro apresentava, em 20I0, um dos piores Índices de Desenvolvimento Social (IDS), como aponta o Instituto Pereira Passos (IPP), aparecendo como o $137^{\circ}$ entre os bairros cariocas. ${ }^{9}$

Considerando sua história, seu potencial de ativismo e seu perfil demográfico e socioeconômico, a experiência da Campanha Maré Diz Não ao Coronavírus será detalhada a seguir, de modo a evidenciar os caminhos percorridos para a proteção social dos moradores, assim como a capacidade de solidariedades latente na sociedade brasileira quando se organiza para agir em prol da coletividade.

\section{A Maré que disse não ao coronavírus}

Quando anunciaram a pandemia, em I3 de março, percebemos logo que muitas famílias não teriam acesso à alimentação. A população já vinha sofrendo com a crise. Com a pandemia, não seria mais possível pedir alimentos: os restaurantes fecharam, muitas pessoas pararam de fazer doações, trabalhadores perderam o emprego. Tínhamos um plantão na Redes e logo começamos a receber pedidos de comida. Ao mesmo tempo,

\footnotetext{
${ }^{7}$ A ONG Redes da Maré, fundada por moradores locais, tem como objetivo central melhorar os indicadores sociais e de violência da região, contribuindo para a melhoria da qualidade de vida de seus moradores. Para isso, realiza projetos estruturantes por meio dos seguintes eixos de trabalho: Educação; Arte e Cultura; Memórias e Identidades; Desenvolvimento Territorial; e Segurança Pública e Acesso à Justiça. Para mais informações sobre os projetos, acesse: www.redesdamare.org.br.

${ }^{8}$ O Censo da Maré foi realizado em 2019 como um projeto do eixo de Desenvolvimento Territorial. Disponível em: <https://www.redesdamare.org.br/media/downloads/arquivos/CensoMare_WEB_04MAl.pdf>.Acesso em: 10 mar. 2021.

${ }^{9}$ Disponível em: <http:// www.data.rio/datasets?q=IDS>. Acesso em: jan. 2018.
} 
alguns parceiros começaram a entrar em contato, perguntando o que pretendíamos fazer. Havia uma sensação de emergência. (SOUSA SILVA; AROUCA, 202I, p. 36)

Como observado pelo relato de Eliana Sousa Silva, na citação anterior, mais do que uma campanha local, a atuação da Redes da Maré teve início com uma ampla movimentação social para arrecadação de doações, e distribuição de materiais de higiene e alimentos para os moradores da Maré. O primeiro passo, contudo, foi localizar esses moradores com perfil socioeconômico mais vulnerável, e estimar a demanda real por auxílio. Para tanto, além de identificar um conjunto de casos prioritários para atendimento em suas bases de dados consolidadas pelos mais de 50 projetos ativos na organização e realizar mais de I 2 mil entrevistas sociais com os moradores, a ativação da parceria com as demais instituições locais foi decisiva para garantir maior alcance.

Assim, juntaram-se a essa empreitada importantes grupos que atuam na região, como as ONGs Luta pela Paz, Uerê, Vida Real e Observatório de Favelas, bem como as I6 associações de moradores das comunidades do bairro. Além disso, as ações tiveram o apoio dos equipamentos sociais públicos locais, como o Centro de Atenção Psicossocial Infantil (CAPSi) Visconde de Sabugosa, o Centro Terapêutico Bonsucesso e o programa Territórios Sociais do Instituto Pereira Passos, configurando uma corrente solidária orientada à promoção do acesso às doações e aos demais desdobramentos de atendimento às famílias da Maré.

Dentre os parceiros institucionais, apoiadores e financiadores, destacaram-se: Instituto Unibanco, Itaú Social, Itaú Cultural, Banco Itaú, Banco da Providência, Fundação Banco do Brasil, Fundação Oswaldo Cruz (Fiocruz), SAS Brasil, Máscara para Todos, Dados do Bem, Rede Solidária, Abong, Unicef, Vale, Sesc RJ, além de muitas outras empresas, associações e doadores individuais que se mobilizaram para que a campanha obtivesse os recursos necessários, bem como apoio não financeiro, logístico, doações de itens, materiais, serviços, oportunidades etc.

Os números consolidados pelo Relatório da Campanha (REDES..., 2020), referentes ao período de março a outubro de 2020 , são impressionantes e traduzem a força da rede de ativismo mobilizada. Foram mais de R\$ 15 milhões arrecadados, 54.709 pessoas beneficiadas, 6.71 2 testes para detecção de Covid-I9 realizados, I.980 toneladas de alimentos distribuídos e 17.648 famílias que receberam cestas de alimentos e kits de higiene. Foram distribuídas mais de 280 mil máscaras para a população, produzidas por 54 costureiras moradoras locais - dentre as ações de incentivo à geração de renda - e 65 mil refeições 
distribuídas para pessoas em situação de rua - preparadas por 22 cozinheiras locais. E mais de mil ruas e vielas foram higienizadas para prevenção de contágio da população.

Ações informativas foram estruturadas para a disseminação de conteúdos relativos aos cuidados de prevenção da Covid-I9 e ao acesso aos serviços públicos e aos benefícios da própria campanha. Para isso, mais de 70 mil mensagens de WhatsApp foram disparadas por meio de listas de transmissão e um conjunto de ações de comunicação foi estabelecido com os boletins De Olho no Corona (25 edições), podcast semanal para veiculação aos moradores (20 episódios) e 568 artigos, matérias e reportagens divulgadas na imprensa. Cerca de 300 voluntários atuaram diariamente para a realização de ações diversas que se organizaram de acordo com as seis frentes descritas a seguir.

\section{Segurança alimentar e nutricional}

Essa frente de atuação realizou a entrega de cestas básicas com alimentos e itens de higiene pessoal e de limpeza em cada domicílio beneficiado, além da transferência direta de renda por meio de cartões de crédito pré-pagos, indo ao encontro das necessidades de subsistência e necessidades sanitárias mais básicas da população. Os itens foram destinados às famílias mais vulneráveis da Maré, negligenciadas pelas políticas públicas que deveriam garantir seus direitos, como aqueles que não recebiam o Auxílio Emergencial oferecido pelo governo federal por dificuldade de acesso e com faixa de renda familiar abaixo de um salário mínimo, além de famílias numerosas, chefiadas por mulheres desempregadas, com demandas de saúde e deficiências.

Inicialmente, a campanha idealizou alcançar 6 mil famílias que haviam sido identificadas como mais vulneráveis, com base nos dados do Censo Populacional da Maré, realizado pela Redes. ${ }^{10}$ Porém, com a condução da distribuição e visível demanda adicional solicitada por mais famílias, foram abertas inscrições aos que desejassem se candidatar ao benefício. No período, 21.II8 pessoas entraram em contato para se inscrever.

O processo de seleção dos inscritos se mostrou bastante criterioso, considerando diferentes faixas de renda para atendimento, de acordo com o perfil da família e de seus integrantes. Dentre os critérios estavam a renda familiar per capita, o número de pessoas na residência (famílias com crianças com menos de seis anos eram priorizadas), as condições de moradia (quantidade de cômodos e se pagavam aluguel) e as condições de saúde dos membros da família (que demandam cuidados adicionais e custos com remédios).

\footnotetext{
${ }^{10}$ Censo populacional realizado pela Redes da Maré, em 2019. Disponível em: <https://www.redesdamare.org.br/media/downloads/arquivos/CensoMare_WEB_04MAl.pdf>. Acesso em: 18 mar. 2021.
} 
As informações foram obtidas por um procedimento de entrevistas sociais conduzidas presencial e remotamente a partir do contato de inscrição, e buscou coletar, além dos dados básicas para admissão ao benefício, dados adicionais sobre acesso à educação, saúde e segurança, dando encaminhamentos específicos para cada caso e consolidando um banco de dados consistente sobre a situação de vida dessas famílias, o qual pode fundamentar novas ações em seu benefício.

\section{Atendimento às populações em situação de rua}

As pessoas em situação de rua configuram-se num grupo dos mais socialmente vulneráveis em qualquer contexto, porém em uma pandemia que depende de medidas como o isolamento social e a higiene constante para a prevenção da doença, esse grupo se encontra ainda mais vulnerável. Nesse sentido, a campanha organizou ações de produção e distribuição de refeições, além de dar continuidade aos atendimentos dos redutores de danos que acompanham usuários de crack e outras drogas, em suas diversas demandas, e viabiliza encaminhamentos e articulações com outras instituições públicas.

É importante destacar que a Redes da Maré trabalha há mais de cinco anos com pessoas em situação de rua. Em 2018, a organização inaugurou um local para receber essas pessoas, o Espaço Normal, porém ele precisou ser fechado durante a pandemia. A campanha, contudo, priorizou a segurança alimentar e nutricional das pessoas em situação de rua e representou também uma oportunidade de geração de renda para as mulheres do projeto Maré de Sabores, desenvolvido pela Casa das Mulheres da Maré, mais um equipamento da Redes. A alimentação é uma das principais necessidades das pessoas que não têm domicílio. De março a dezembro de 2020 , o projeto ofereceu 65 mil quentinhas, utilizando 70 toneladas de alimentos. As refeições eram entregues para três grupos: I) pessoas domiciliadas, mas em situação de extrema vulnerabilidade, sem condições e/ou estrutura de produzir o próprio alimento; 2) indivíduos sem domicílio fixo, que alternam entre rua, casa de amigos e abrigos, e iam até o Espaço Normal para pegar seu kit alimentação; e 3) usuários que vivem na cena de consumo de drogas, dentro da Maré e na Avenida Brasil.

\section{Acesso a direitos, cuidados e prevenção em saúde}

Essa frente de atuação concentrou as ações da campanha com foco direto no atendimento de saúde e prevenção à Covid-ı. A equipe de assistentes sociais, advogadas, psicólogas e redutores de danos também passou a atuar no acolhimento e acompanhamento dos casos de moradores contaminados. As informações chegavam através de múltiplas fontes: na entrega das cestas, nas entrevistas sociais, através de parceiros no território e de outras instituições. 
Até julho de 2020, foram atendidas $\mathrm{I} .353$ pessoas com suspeita de contaminação pelo novo coronavírus, das quais quase $70 \%$ não obtiveram acesso a testes e seguiam invisíveis para os órgãos de saúde, com o agravante de que desconheciam o diagnóstico do que as acometia. $\mathrm{O}$ monitoramento e acompanhamento das pessoas com Covid-I9 e dos familiares dos mortos pela doença permitiu qualificar e produzir informações confiáveis, que serviriam de base para produção do boletim semanal De Olho no Corona. ${ }^{11}$

A partir desse mapeamento, foi organizado o projeto Conexão Saúde - De Olho na Covid!, uma parceria entre Redes da Maré, Fiocruz, SAS Brasil, Dados do Bem, União Rio, Conselho Comunitário de Manguinhos e Todos pela Saúde para a oferta gratuita de serviços como testagem de moradores, atendimento médico on-line e um programa de orientações para o isolamento domiciliar seguro. Até dezembro de 2020, o Conexão Saúde havia realizado 6.7I 4 testes, dentre os quais I.220 foram positivos, representando I8\% de confirmações de Covid-I9 entre os casos analisados. Em participação no evento de lançamento on-line do projeto, em I9 de agosto, a pesquisadora Margareth Dalcomo, da Fiocruz, destacou o papel das lideranças comunitárias na execução de projetos de saúde: “As lideranças comunitárias são fundamentais para que nós consigamos ter acesso a essas comunidades. Elas são legítimas representantes não só dessas pessoas, mas como dos problemas que são prevalentes nessas comunidades" (SOUSA SILVA; AROUCA, 202I, p. 69).

A campanha ainda promoveu a arrecadação de equipamentos de proteção individuais (EPIs) e as distribuiu para as unidades de saúde da Maré, numa espécie de política de saúde invertida, na qual é a sociedade civil que provê insumos ao poder público, tendo em vista a necessidade dos profissionais de saúde pelos equipamentos e a baixa oferta pelos governos. Sete Unidades de Atenção Básica, uma UPA, três Centros de Atenção Psicossocial e o Consultório de Rua e a Unidade de acolhimento receberam mais de 37 mil máscaras - cirúrgicas e de pano - além de óculos, protetores faciais, aventais, luvas, capotes e álcool em gel.

De modo semelhante, a campanha promoveu a desinfecção de todas as ruas, vielas e becos da Maré, juntamente a uma brigada de garis mobilizados pela parceria com a Companhia Municipal de Limpeza Urbana do Rio de Janeiro (Comlurb), e realizou a distribuição de álcool em gel e máscaras de tecido para os moradores, ocupando um vazio institucional deixado pelas políticas públicas que não ofereceram os cuidados necessários à população.

De acordo com Sousa Silva e Arouca (202I), garantir o isolamento domiciliar é "especialmente difícil para moradores de favelas, por questões econômicas ou mesmo

\footnotetext{
11 Disponível em: <https://www.redesdamare.org.br/br/publicacoes\#livros>. Acesso em: 15 mar. 2021.
} 
estruturais, como falta de ventilação e/ou saneamento básico". As ações, portanto, tiveram que ser criativas, segundo as autoras, para encontrarem formas de diminuir os riscos de contágio, levando em conta a dificuldade da população, ao mesmo tempo que precisavam chamar atenção do poder público sobre "a necessidade de políticas públicas específicas e prioritárias para regiões de favelas e periferias, assim como de outras comunidades com alto risco de contágio" (p. 7I).

\section{Produção e difusão de informações e conteúdos seguros}

É possível afirmar que o acesso à informação segura e correta sobre procedimentos e cuidados necessários para a proteção social e sanitária na pandemia seja um dos problemas mais graves que acompanham o avanço do contágio da doença em nosso país. Desse modo, dentro de um contexto no qual o conhecimento sobre o vírus e seus efeitos ainda estavam sendo descobertos pela ciência, além da desinformação e notícias falsas espalhadas inclusive por representantes governamentais, mostrou-se imprescindível, de acordo com os executores da campanha, abraçar a frente de produção de informações como uma prioridade absoluta para benefício dos moradores.

Assim, se deu a produção de uma série de materiais de comunicação, em diferentes linguagens, para veiculação em plataformas on-line, como perfis nas redes sociais, site e canais da Redes da Maré. Foram diversos veículos, como podcast, boletins semanais, cartazes, cards para redes sociais, além do Jornal Maré de Notícias que alcança I40 mil pessoas, ou seja, todos os residentes da Maré. A ação colaborou para que moradores tivessem acesso a informações seguras e recomendações de prevenção baseadas em evidências científicas, e acompanhassem a situação da pandemia na Maré e em outras áreas de favela e periferia.

\section{Geração de trabalho e renda}

Tendo em vista a crise econômica e o aumento do desemprego que já acometiam o país e a cidade do Rio de Janeiro, a pandemia acentuou essa situação, de modo que a necessidade de geração de renda é urgente para indivíduos e famílias. Nessa perspectiva, a campanha não só realizou as ações externas já descritas como oportunizou a criação de novos postos de trabalho, tendo como prioridade a contratação de moradores da Maré, com atenção especial às mulheres responsáveis pela renda do domicílio/família e ao reconhecimento e fortalecimento de profissionais locais.

Foram I29 postos de trabalho criados no período, por meio de quatro tipos de contratação: cozinheiras para o projeto Maré de Sabores, que produziram alimentos para 
populações em situação de rua; costureiras, que confeccionaram máscaras; motoristas, que realizaram as entregas de cestas de alimentos e kits de limpeza e higiene pessoal; e moradores que trabalharam na higienização das ruas do bairro.

\section{Apoio a artistas, produtores e grupos culturais locais}

$\mathrm{Na}$ esteira da necessidade de geração de renda, um setor econômico específico vem sofrendo de maneira bastante acentuada, sem acesso a políticas públicas que possam reduzir os impactos da falta de trabalho: o setor da cultura. Segundo a PNAD, em 20I8, o setor cultural contava com cerca de 5 milhões de trabalhadores, dos quais $44 \%$ trabalhavam como autônomos. ${ }^{12}$

Assim, a campanha realizou a seleção e o financiamento de projetos voltados ao reconhecimento e fortalecimento dos artistas locais, incentivando as expressões artísticas dos moradores que pensassem suas atividades no novo contexto de distanciamento social. O edital "Novas formas de fazer arte, cultura e comunicação nas favelas" contribuiu com a sustentabilidade mínima para seus projetos artísticos, culturais e comunicacionais, tendo sido contemplado pela Lei de Incentivo à Cultura, com a poio do Itaú Cultural e do People's Palace Projects. Foram oferecidas 3I bolsas de incentivo, nos valores de R\$ 3.00o, R\$ 5.000 e R $\$$ I0.000 para criadores de literatura, artes plásticas, audiovisual, dança, teatro, música, podcast e fotografia/texto.

Diante dos dados expostos e da profusão de ações desempenhadas por essa campanha da sociedade civil, salta aos olhos que o esforço realizado por um conjunto de atores surtiu efeitos decisivos na manutenção da vida de milhares de pessoas que residem nas favelas da Maré. Alguns depoimentos dos próprios beneficiados e voluntários, contidos na publicação Maré Diz Não ao Coronavírus: a jornada da Redes da Maré por saúde e direitos em meio à pandemia (SOUSA SILVA; AROUCA, 2O2I) - fruto da própria campanha -, traduzem de maneira sensível os resultados evidenciados até aqui. São casos de famílias numerosas que se viram sem renda, sem merenda da escola e sem escolarização; ou casos de pessoas que perderam o emprego e encontraram no voluntariado uma oportunidade de ajudar e ser ajudado, conforme trechos a seguir (modificados para preservar as identidades).

\footnotetext{
${ }^{12}$ Disponível em: <https://agenciadenoticias.ibge.gov.br/agencia-noticias/2012-agencia-de-noticias/noticias/26238participacao-da-cultura-no-orcamento-reduz-em-todas-esferas-de-governo-em-2018>. Acesso em: 24 mar. 2021.
} 


\section{Voluntária que virou articuladora}

Fui entregar uma cesta e a vizinha disse: "Eu me inscrevi, mas a minha não chegou". Eu disse que ia chegar, para ela aguardar. Mas quando fomos sair, ela me puxou, me levou pra cozinha e abriu o armário. Não tinha nada na casa dela. E ela desesperada: "Eu não sei o que vou comer". Quando cheguei lá na Redes, ela tinha feito a inscrição, e liberou a cesta. Foi gratificante saber que ela ia ter o que comer. Para mim, também ficou complicado. Tinha de sobreviver com o dinheiro da pensão das minhas filhas e a ajuda da minha mãe. Eu também recebi da Redes da Maré um cartão com um saldo de 215 reais, que podia usar para comprar remédio ou o gás. Isso ajudou. Hoje sou articuladora no projeto Conexão Saúde.

2. Desempregado que virou tecedor ${ }^{13}$

É emocionante encostar o carro na porta da pessoa, tirar a cesta, e a pessoa vir e te agradecer. Agradecer a Redes da Maré. E a Redes fez um trabalho tão correto que ia justamente naquela pessoa que estava precisando mesmo. E se a pessoa não estava precisando, chegava e falava: "Eu não estou precisando, cara, pode levar de volta". Vinham pessoas chorando, gente que tinha perdido a esperança. Minha profissão era a de vendedor de cervejaria. Eu vivia que nem um doido pra vender, bater a meta. Brabo. Nervoso. A Redes me fez conhecer o outro lado da vida. Eu não era pago, mas ganhava a cesta. Depois de 28 anos de trabalho, a empresa me "chutou", falando que eu não tinha mais perfil para trabalhar. Em agosto, no meio da pandemia. Fiquei sem chão. Não tinha como desenrolar com ninguém. Mas agora sou tecedor da Redes, estou trabalhando.

3. Beneficiária de cesta básica, mãe solteira

A cesta foi uma ajuda maravilhosa. Veio em um momento muito difícil. A gente não tinha nada dentro de casa. O pai deles [dos filhos] foi embora em janeiro. Quem me cadastrou foi a enfermeira do posto de saúde. Eu estava grávida quando chegou a primeira cesta. Meu filho nasceu na pandemia. Ter filho na pandemia foi muito complicado. Não podia receber visita. Só recebo ajuda da minha mãe e 269 reais do Bolsa Família. Eles comem bem, querem repetir o almoço, a janta. Como está

\footnotetext{
13 O termo "tecedor" se refere aos profissionais que atuam na Redes da Maré.
} 
muito apertado, eu fico controlando: "Não, calma, na janta vocês repetem". Com a cesta, eu deixei de comprar arroz, óleo, pra comprar carne, fralda, sabonete, essas coisas. Fiquei com medo da pandemia. Eu tenho asma e minha filha tem bronquite. Tinha gente que falava que se a gente pegasse [o vírus] não ia aguentar, porque é muito forte. Nem pra casa da minha mãe a gente ia, pois ela é diabética. A gente ia ao mercado e voltava pra casa. No máximo ficava na rua ali em frente. Se emprego já tava difícil, na pandemia piorou. Quero arrumar um trabalho, pagar minha irmã pra ficar com as crianças e esperar a escola voltar.

\section{Beneficiária de cesta básica, mãe de cinco crianças}

A cesta básica ajudou muito. Vinha uma cesta boa, com muita coisa. Mas não durava nem duas semanas, porque meus filhos comem muito. Quando tinha escola, eles ficavam lá das $7 \mathrm{~h}$ da manhã às $3 \mathrm{~h}$ da tarde. Tomavam café, almoçavam, e na saída ainda comiam uma fruta. Chegavam em casa, jantavam e iam dormir. Não ficavam o dia todo comendo. Os meus quatro filhos que vão à escola não tiveram aula em 2020, nem pela internet. Se tivessem, não sei como iria fazer: não tenho como botar internet pra eles. Nem pelo celular, porque o meu está ruim. As crianças ficam brincando, sem fazer nada. É muito mais perigoso. Já tive de sair pra rua no meio de bala pra tirar meus filhos. Não é seguro.

\section{O perfil de vulnerabilidade na pandemia}

Esses depoimentos nos fazem pensar sobre o perfil das pessoas beneficiadas na Maré, considerando que se trata de uma amostra de parcela considerável da população brasileira, numa escala possível de aferição, de acordo com os dados obtidos pela campanha. Dentre as I7.648 famílias da Maré que receberam as doações da campanha, II.435 passaram por entrevista social, consolidando a base para a análise de seu perfil.

Considerando que $46,8 \%$ das famílias beneficiadas agregavam quatro ou mais pessoas no mesmo domicílio, estima-se que os benefícios alcançaram 54 mil indivíduos moradores das 16 favelas da Maré. As mulheres foram apontadas como as responsáveis pela família na grande maioria $(79,1 \%)$ dos domicílios, um dado que corresponde à desigualdade de gênero na divisão do trabalho doméstico. Ainda, dentre as mulheres atendidas, 7I\% eram negras, somando pretas e pardas, o que evidencia a natureza interseccional de gênero e raça no perfil de vulnerabilidade social. Considerando tanto 
homens quanto mulheres que recorreram à campanha, o total de negros também se mostrou predominante, alcançando $68,7 \%$ das pessoas atendidas pela campanha.

Sobre a condição de renda familiar, o perfil de pobreza e insegurança econômica chamou muita atenção, pois mais da metade das pessoas assistidas $(6 \mathrm{I}, 8 \%)$ informou que nenhum morador do seu domicílio estava trabalhando. Esse dado é revelador para um cenário de crescimento exponencial do desemprego no país, apontando o fato de que as medidas governamentais de proteção da economia nacional não priorizaram a manutenção dos empregos da classe trabalhadora. Em relação à renda atual declarada nas entrevistas, a maioria vivia com renda per capita inferior a meio salário mínimo: aproximadamente 33\% contavam com renda de até $\mathrm{R} \$ 26 \mathrm{I}, 25$ per capita, e outros $33 \%$ contavam com $\mathrm{R} \$ \mathbf{5 2 2 , 5 0}$ per capita. Em níveis ainda mais graves, $\mathrm{I} 2 \%$ se encontravam totalmente sem renda, em situação de extrema de pobreza.

Por outro lado, as políticas de distribuição de renda merecem ser valorizadas, de modo que sem elas o quadro social teria sido muito mais trágico. Quase 60\% das famílias atendidas pela campanha recebiam algum benefício social de complementação de renda: $84 \%$ dos entrevistados afirmaram receber apenas o auxílio emergencial, o que demonstra a necessidade urgente de sua distribuição e manutenção, pois, sem ele, essas famílias ficarão sem renda alguma. Entretanto apenas $22,9 \%$ dos beneficiados afirmaram receber o benefício do Bolsa Família, e I6,2\% algum outro, como o Cartão Família Carioca e o Benefício de Prestação Continuada (BPC), revelando uma pequena parcela da população que está sendo devidamente assistida pelo Estado.

A análise da questão da renda ganha contornos mais objetivos quando acompanhada da compreensão sobre a composição familiar, de modo a se avaliar o quanto o acesso a esses benefícios ainda dependia da distribuição interna dos recursos para demandas específicas de cada família. Ao todo, 4I,6\% dos domicílios assistidos tinham mais de uma criança de até 6 anos de idade e I9,I\% contavam com algum morador idoso com mais de 60 anos, dados que apontam necessidades de cuidados adicionais e maior vulnerabilidade dessa população. Em termos de saúde, em 44,3\% dos domicílios havia algum morador com demanda de saúde, estando entre as mais citadas doenças crônicas como diabetes, hipertensão ou problemas respiratórios, precisamente os tipos de comorbidades que caracterizam os grupos de risco da Covid-I9.

Fica nítido, portanto, que as ações direcionadas a esse público foram determinantes para sua sobrevivência em meio à crise pandêmica. Diante de uma população historicamente marcada por constrangimentos ocasionados pela desigualdade social brasileira, a sociedade civil mostrou ser possível a construção de soluções, mesmo que temporárias, para a garantia dos direitos fundamentais e de um mínimo bem-estar social. 


\section{Conclusão}

A experiência de ativismo periférico conduzida pela organização não governamental Redes da Maré traz algumas reflexões e aprendizados importantes para o debate sociológico em torno do associativismo brasileiro, dos movimentos sociais e da participação democrática.

Em primeiro lugar, podemos afirmar que a sociedade civil mobilizada para a sobrevivência popular diante da pandemia vem reafirmando sua centralidade na promoção da ação coletiva em busca de direitos. Que apesar dos desgovernos instituídos pela política eleitoral, a força da solidariedade recai sobre indivíduos, coletivos e instituições organizadas por um sentimento de urgência e pela confiança mútua entre os setores público, social e privado, orientados pela responsabilidade social. Não seria possível um movimento tão expressivo como foi a campanha da Maré sem que instituições privadas e associações acadêmicas confiassem no trabalho das organizações sociais, e sem que estas tivessem legitimidade perante a população e os equipamentos públicos locais. $O$ que se afirma com isso é que, independentemente da política institucional, uma potente rede de proteção social foi consolidada e ativada com um objetivo comum, amparada pela diversidade dos apoios e da força de trabalho disponíveis.

A campanha, nesse sentido, pode ser observada como um disparador de forças sociais que, para além de uma ação pontual e temporária, possam se manter ativas e em diálogo para compor uma ação coletiva permanente, tendo em vista o fato de que as consequências da crise social atual não se esgotarão brevemente. Ao contrário, com a virada para $202 \mathrm{I}$, estão previstos o recrudescimento da pandemia, o aprofundamento da crise econômica somada à interrupção do auxílio emergencial, e a ampliação do desemprego, da fome e da pobreza, produzindo um cenário sobre o qual, no vácuo das políticas públicas, caberá à sociedade como um todo o trabalho de criar respostas ágeis e eficazes para a temporização dos riscos sociais sobre os mais vulneráveis. Não por acaso, o esforço realizado recebeu dois prêmios pelo reconhecimento de seus resultados: o de Empreendedor Social do Ano 2020, da Folha de S. Paulo, na categoria "Legado Pós-Pandemia"; e o Carolina Maria de Jesus de Direitos Humanos, concedido pela Assembleia Legislativa do Rio de Janeiro.

Em segundo lugar, é digna de nota a reflexão sobre a situação da Maré como um território historicamente deflagrado pela violência de Estado, no qual a existência de uma sociabilidade violenta não compromete a capacidade da ação coletiva e, em muitos casos, a incita, diante das inúmeras violações de direitos. Apesar da presença de grupos criminosos de todos os tipos nessa região, são as operações policiais as maiores responsáveis pelos sentimentos de ameaça à vida dos moradores, conforme sinalizam as pesquisas conduzidas pelo eixo de Segurança Pública da Redes da Maré. Editado há quatro 
anos, o Boletim Direito à Segurança Pública na Maré, sistematizou dados referentes aos impactos da violência armada no conjunto das I6 favelas da Maré. Segundo a publicação, em 2019, os moradores conviveram com 300 horas de operações policiais por ano, além de um recorde de mortes por violência armada, com 49 vidas perdidas, sendo 34 em decorrência de ações policiais.

Nesse sentido, o potencial de ativismo consolidado nessa experiência liderou uma frente nacional pelo fim das operações policiais em favelas, considerando o momento da pandemia como um exemplo evidente de como essas operações, além de serem ineficazes do ponto de vista do enfrentamento ao narcotráfico e ao tráfico de armas, colocam em risco a vida dos moradores cotidianamente, e ainda mais num contexto onde as pessoas precisam praticar o isolamento social e estão mais vulneráveis dentro da própria casa. Em 20ı6, a Redes da Maré se uniu à Defensoria Pública do Estado para mover uma Ação Civil Pública (ACP) contra o estado do Rio de Janeiro para a regulação das operações policiais. ${ }^{14}$ Esta experiência motivou a Redes a participar da Arguição de Descumprimento de Preceito Fundamental no 635, apelidada da ADPF das Favelas, proposta ao Supremo Tribunal Federal (STF), dessa vez, destinada à suspenção das operações. ${ }^{15} \mathrm{Em}$ junho de 2020, foi proferida uma liminar de aceite da proposta, com resultados visíveis de imediato. De acordo com o Grupo de Estudos de Novos Ilegalismos da Universidade Federal Fluminense (HIRATA, 2O2I) houve uma diminuição de mortes da ordem de $73 \%$ em junho de 2020, em comparação com o mesmo período de 2019. Ao mesmo tempo, houve redução expressiva dos crimes contra o patrimônio (39\%) e contra a vida ( $47 \%)$ em toda a região metropolitana do estado.

Desse modo, a experiência da campanha vem surtindo resultados para a realocação do debate sobre as favelas perante a opinião pública, na medida em que vem evidenciando as condições de vida de seus moradores por meio da urgência humanitária em curso, além de convocar a sociedade a estabelecer com elas uma relação de maior reciprocidade solidária. De acordo com Eliana Sousa Silva (SOUSA SILVA; AROUCA, 202I), "quem só ouvia falar da favela pela violência passou a enxergá-la a partir do coronavírus". ${ }^{16}$

\footnotetext{
${ }^{14}$ Concedida pelo Poder Judiciário fluminense, a ACP exigia respeito a direitos da população da Maré e forçava o Estado a agir dentro da lei, derrubando mandados coletivos e criando parâmetros para as ações policiais, como a presença de ambulâncias, viaturas com câmera de áudio, vídeo e GPS, além de um plano de redução da letalidade construído coletivamente.

${ }^{15}$ Ação apresentada pelo Partido Socialista Brasileiro (PSB) e construída coletivamente com a Defensoria Pública do Estado do Rio de Janeiro, a Educafro, a Justiça Global, a Conectas Direitos Humanos, o Movimento Negro Unificado, o Instituto de Estudos da Religião (ISER), a Iniciativa Direito à Memória e Justiça Racial (IDMJR), o Coletivo Papo Reto, o Coletivo Fala Akari, a Rede de Comunidades e o Movimento Mães de Manguinhos.

${ }^{16}$ Depoimento concedido em entrevista para o El País, em março de 2020. Disponível em: <https://brasil.elpais.com/sociedade/2020-03-28/sousa-da-redes-da-mare-quem-so-via-a-favela-pela-violencia-passou-aenxerga-la-a-partir-do-coronavirus.html?rel=listapoyo>. Acesso em: 22 mar. 2021.
} 
De todo modo, a situação das favelas permanece obtusamente grave, tendo em vista o aprofundamento das desigualdades históricas acentuadas pela pandemia. Conforme vem apontando a Organização Mundial de Saúde (OMS), o número de infectados e mortos está diretamente relacionado à qualidade e à agilidade das medidas protetivas tomadas pelos diferentes países. No Brasil, enquanto as mortes já ultrapassam a casa dos $400 \mathrm{mil}$, o governo federal mantém o discurso negacionista e a política genocida, sem liderar uma ação coordenada e eficaz de proteção da população, que se mantém alheia à importância do isolamento social e não pratica com seriedade os protocolos de segurança, facilitando a expansão da doença. A liderança crucial da sociedade civil no processo de socorro à população e de produção de medidas protetivas, portanto, assume importância inédita na conjuntura nacional e se mantém necessária.

Não é possível, contudo, prescindir da atuação das políticas públicas como efetivadoras de direitos, sendo sua responsabilidade institucional promover as condições básicas para a cidadania plena da população, com especial ênfase sobre aqueles grupos mais vulneráveis, como os de crianças, adolescentes e jovens, idosos, negros, indígenas, LGBTQ+, mulheres e pobres. Por mais bem estruturadas e qualificadas que sejam as ações conduzidas pela sociedade civil, elas não têm a escala de universalização que apenas o Estado pode alcançar.

\section{Referências}

BARBOSA, J. L.; SILVA, J. de S. e. As favelas como territórios de reinvenção da cidade. Cadernos do Desenvolvimento Fluminense, Fundação CEPERJ/UERJ, Rio de Janeiro, n. I, fev. 2013.

BARROS, A. Desemprego recua para $13,9 \%$ no $4^{\circ}$ tri, mas taxa média do ano é a maior desde 2012. Agência IBGE de Notícias. 26 fev.2O2I. Editoria Estatísticas Sociais. Disponível em: $<$ https://agenciadenoticias.ibge.gov.br/agencia-noticias/20I2-agencia-denoticias/noticias/30I30-desemprego-recua-para-I3-9-no-quarto-trimestre-mas-e-omaior-para-o-ano-desde-2OI2>. Acesso em: I2 abr. 2O2I.

BURGOS, M. Dos parques proletários ao Favela Bairro: as políticas públicas nas favelas do Rio de Janeiro. In: ZALUAR, A.; ALVITO, M. Um século de favela. 5. ed. Rio de Janeiro: Editora FGV, 2006.

\section{CONTRIBUIDORES DA WIKI DICIONÁRIO DE FAVELAS MARIELLE FRANCO.}

Resultados - Covid-I9 nas favelas. Rio de Janeiro, 25 jul. 2020. Disponível em: $<$ https://wikifavelas.com.br/index.php?title=Resultados_-_Covid-I9_nas_favelas $>$. Acesso em: I5 de abr. 202I. 
FERNANDES, F. et al. O paradigma da potência e a pedagogia da convivência. Revista Periferias, Instituto Maria e João Aleixo, UNIperiferias, Rio de Janeiro, v. I, 2018. Disponível em: $<$ https://revistaperiferias.org/materia/o-paradigma-da-potencia-e-apedagogia-da-convivencia/>. Acesso em: IO abr. 202I.

HIRATA, D. (Coord.). Operações policiais e violência letal no Rio de Janeiro: os impactos da ADPF 635 na defesa da vida. Relatório de pesquisa - Grupo de Estudos de Novos Ilegalismos, Universidade Federal Fluminense, Niterói. 202I. Disponível em: $<$ http://geni.uff.br/2021/04/05/operac\%cc\%a7o\%cc\%83es-policiais-eviole\%cc\%82ncia-letal-no-rio-de-janeiro-os-impactos-da-adpf-635-na-defesa-davida/>. Acesso em: $20 \mathrm{abr}$. 2O2I.

MELO, M. L. Primeira vítima do RJ era doméstica e pegou coronavírus da patroa no Leblon. UOL, Rio de Janeiro, I9 mar. 2020. Disponível em: $<$ https://noticias.uol.com.br/saude/ultimas-noticias/redacao/2020/o3/19/primeiravitima-do-rj-era-domestica-e-pegou-coronavirus-da-patroa.htm $>$. Acesso em: 20 jan. 2O2I.

MINISTÉRIO DA SAÚDE gastou menos de um terço do dinheiro disponível para combate à pandemia, diz TCU. GI, Brasília, 22 jul. 2020. Disponível em: $<$ https://gI.globo.com/politica/noticia/2020/07/22/ministerio-da-saude-gastoumenos-de-um-terco-do-dinheiro-disponivel-para-combate-a-pandemia-diztcu.ghtml>. Acesso em: 12 mar. 202I.

NÓBREGA JÚNIOR, E. D. Memória e identidade dos moradores de Nova Holanda. Rio de Janeiro: Redes de Desenvolvimento da Maré, 2012.

OBSERVATÓRIO DAS METRÓPOLES. Impactos da pandemia nos territórios populares do Rio de Janeiro. I2 nov. 2020. Disponível em: $<$ https://www.observatoriodasmetropoles.net.br/impactos-da-pandemia-nosterritorios-populares-do-rio-de-janeiro-breve-analise-do-levantamento-daarticulacao-por-direitos-na-pandemia/>. Acesso em: I5 de abr. $202 \mathrm{I}$.

SILVA, L. A. M. da. Sociabilidade violenta: por uma interpretação da criminalidade contemporânea no Brasil urbano. Soc. estado, Brasília, v. I9, n. I, p. 53-84, jun. 2004. Disponível em: $<$ http://www.scielo.br/scielo.php?script=sci_arttext\&pid=SoIO2$69922004000100004 \& \operatorname{lng}=\mathrm{en} \& \mathrm{nrm}=$ iso $>$. Acesso em: 25 abr. 2021.

SOUSA SILVA, E.; AROUCA, L. Maré Diz Não ao Coronavírus: a jornada da Redes da Maré por saúde e direitos em meio à pandemia. Rio de Janeiro: Mórula, 2O2I.

SOUSA SILVA, E.; MARINHO, D. (Coord.). Censo populacional da Maré. Rio de Janeiro: Redes de Desenvolvimento da Maré, 2018. 
SOUZA E SILVA, J. de; BARBOSA, J. L. Favela: alegria e dor da cidade. São Paulo: Senac; Rio de Janeiro: $\mathrm{X}$ - Brasil, 2005.

REDES DE DESENVOLVIMENTO DA MARÉ. Campanha Maré Diz Não ao Coronavírus.

Relatório de Atividades da Campanha 2020. Rio de Janeiro, 2020. Disponível em:

$<$ https://www.redesdamare.org.br/media/downloads/arquivos/RdM_Relatorio_campa nha.pdf $>$. Acesso em: I3 fev.2O2I

TORO, J. B.; WERNECK, N. M. D. F. Mobilização social: um modo de construir a democracia e a participação. Belo Horizonte: Autêntica, 2007.

VALLADARES, L. do P. A invenção da favela: do mito de origem à favela.com. Rio de Janeiro: Ed. FGV, 2005. 204 p. 